\title{
The Effects of Systemic and Local Acidosis on Insulin Resistance and Signaling
}

\author{
Nicola Baldini ${ }^{1,2}$ and Sofia Avnet $1, * \mathbb{( 1 )}$ \\ 1 Orthopaedic Pathophysiology and Regenerative Medicine Unit, Istituto Ortopedico Rizzoli IRCCS, \\ 40136 Bologna, Italy; nicola.baldini@ior.it \\ 2 Department of Biomedical and Neuromotor Sciences, University of Bologna, 401223 Bologna, Italy \\ * Correspondence: sofia.avnet@ior.it; Tel.: +39-051-636-6566
}

Received: 13 October 2018; Accepted: 23 December 2018; Published: 30 December 2018

\begin{abstract}
Most pathological conditions that cause local or systemic acidosis by overcoming the buffering activities of body fluids overlap with those diseases that are characterized by glucose metabolic disorders, including diabetes mellitus, inflammation, and cancer. This simple observation suggests the existence of a strong relationship between acidosis and insulin metabolism or insulin receptor signaling. In this review, we summarized the current knowledge on the activity of insulin on the induction of acidosis and, vice versa, on the effects of changes of extracellular and intracellular $\mathrm{pH}$ on insulin resistance. Insulin influences acidosis by promoting glycolysis. Although with an unclear mechanism, the lowering of $\mathrm{pH}$, in turn, inhibits insulin sensitivity or activity. In addition to ketoacidosis that is frequently associated with diabetes, other important and more complex factors are involved in this delicate feedback mechanism. Among these, in this review we discussed the acid-mediated inhibiting effects on insulin binding affinity to its receptor, on glycolysis, on the recycling of glucose transporters, and on insulin secretion via transforming growth factor $\beta$ (TGF- $\beta$ ) activity by pancreatic $\beta$-cells. Finally, we revised current data available on the mutual interaction between insulin signaling and the activity of ion/proton transporters and $\mathrm{pH}$ sensors, and on how acidosis may enhance insulin resistance through the Nuclear Factor kappa B (NF- $\mathrm{B}$ ) inflammatory pathway.
\end{abstract}

Keywords: insulin receptor; acidosis; glucose metabolism; ion/proton transporters; acid-sensing ion channels

\section{Introduction}

Acid-base homeostasis and $\mathrm{pH}$ regulation are critical for both normal physiology and cell function, and is subjected to strong regulation. Precise maintenance of $\mathrm{pH}$ is needed, both at the extracellular level and in the cytosol, since changes in the extracellular space immediately impact on the intracellular cytosolic $\mathrm{pH}$, and the cell machinery is very sensitive to changes in intracellular $\mathrm{H}^{+}$concentration. To maintain the acid-base balance, extracellular $\mathrm{pH}$ is usually kept around neutral values and within narrow limits. The most important examples are arterial blood $\mathrm{pH}$ that is maintained between 7.36 and 7.44, or the $\mathrm{pH}$ of the venous blood that is around 7.6. As an immediate mechanism of defense against $\mathrm{pH}$ changes, several intracellular and extracellular buffers are available at different body districts. In the blood, the most important is the $\mathrm{HCO}_{3}{ }^{-} / \mathrm{CO}_{2}$ buffer system, but hemoglobin or plasma proteins also substantially contribute to the buffering activity with their numerous histidine residues. In addition, other proteins with histidine residues at other body districts, or citrate and hydroxyapatite in bone, have strong alkalinizing activity. Notably, interstitial fluids contain little $\mathrm{pH}$ buffering molecules and, at this level, the $\mathrm{pH}$ is likely to be lower and subjected to a more complex and dynamic gradient. In this case, the $\mathrm{pH}$ value varies strongly depending on the type of specific 
tissue, on the individual cell metabolic activity, and on the distance of the specific cell from the nearest capillary vessel. Due to technical difficulties, this has not been a well-investigated area. However, next-generation techniques allow for the real time measurement of live-cell metabolism, intracellular $\mathrm{pH}$, and proton pumping, both through imaging instrumentations and biochemical assays, thereby opening up the possibility for a better comprehension of the phenomenon for the future.

Different pathological conditions may cause an overcoming of the buffering activities in bodily fluids. A multitude of potential causes of systemic and local acidosis exists. Local acidification may result from growth factors or cytokine stimulation of cell metabolism, vascular disease, ischemia, infection, tumors, or inflammation [1-4]. In fracture healing, immediately after the initial trauma, fracture hematoma is characterized by hypoxia and low $\mathrm{pH}$ [5]. Furthermore, as demonstrated by Marunaka et al., even in pre-disease stages, $\mathrm{pH}$ is drastically lowered in interstitial fluids around various tissues, including the brain [6]. At a systemic level, in addition to renal and respiratory diseases, a source of excessive accumulation of $\mathrm{H}^{+}$are anaerobic exercise, gastroenteritis, the excessive consumption of proteins or of other acidifying substances, anemias, acquired immunodeficiency syndrome (AIDS), aging, and menopause, and last but not least, diabetes. Remarkably, most of the aforementioned situations overlap with those which occur with an altered glucose or insulin metabolism, suggesting a strong relationship between acidosis and insulin metabolism or insulin receptor signaling.

Insulin is the most potent physiological anabolic known agent, promoting the storage and synthesis of lipids, protein, and carbohydrates, and inhibiting their breakdown and release into the body's circulation [7]. Insulin is particularly active in muscle and liver cells and is also often coupled with fatty acid uptake, especially in adipose cells [8]. However, all mammalian cells virtually possess insulin receptors (IR), and hence respond to insulin. Additional notable insulin target cells with a metabolic function include macrophages, endothelial cells, and insulin-producing pancreatic $\beta$-cells [9].

In this review, we described how insulin activity modulates $\mathrm{pH}$ regulation, and vice versa, how changes in $\mathrm{pH} —$ both at the extracellular or the intracellular compartments—regulate insulin signaling and glucose metabolism.

\section{Insulin-Mediated Increase of Glycolysis and Local Acidosis}

One of the major functions of insulin is a stimulatory effect on glycolysis that occurs when there is a rise in the level of circulating glucose. In turn, glycolysis causes lactic acid production. Hyperlactatemia is a recurrent clinical feature of diabetic patients [10] and has been directly associated with acidosis through a cause-and-effect relationship. However, the correlation between the high blood concentration of lactate and acidosis in diabetes is far from being clear. In a clinical context, lactic acidosis can occur either due to excessive production of lactate at the tissue level or impaired lactate metabolism. Notably, hyperlactatemia may also occur with a normal serum $\mathrm{pH}$ or with alkalosis due to the presence of a mixed acid-base disturbance, where a concomitant respiratory or metabolic alkalosis masks the effect of the elevated lactic acid concentrations.

In more detail, regarding the excessive production of lactate, it is important to note that it has often been mistakenly thought that acidosis associated with lactic acid production is due to the dissociation of lactic acid and formation of $\mathrm{H}^{+}$[11]. Already in 2004, Robergs disproved this conception by showing that the reaction catalyzed by lactic dehydrogenase (LDH) produces lactate and not lactic acid, and that production of lactate rather consumes $\mathrm{H}^{+}$[12]. Based on the same concept, more recently, Corbet et al. discussed that lactate and $\mathrm{H}^{+}$ions are separate entities [13]. In particular, under deep hypoxia, lactate and $\mathrm{H}^{+}$are produced independently and only limited fractions of each combine to form lactic acid, as the $\mathrm{pKa}(\sim 3.9)$ for the carboxyl hydrogen dissociation remains well below cytosolic $\mathrm{pH}$ and even extracellular $\mathrm{pH}$. Furthermore, when most glucose-derived pyruvate is reduced into lactate, the full conversion of glucose into two lactate molecules and two $\mathrm{H}^{+}$ions in hypoxic cancer cells is only theoretical since some glucose molecules are diverted into other metabolic pathways [13]. However, 
the lactate gradient across the cell membrane influences $\mathrm{H}^{+}$efflux since lactate is transported across the cell membrane by monocarboxylic acid transporters (MCT), mainly by the MCT4, through a symport of $\mathrm{H}^{+}$across the cell membrane [14]. Finally, once lactate reaches the extracellular space, the lactate-based acid-base balance is influenced by several interacting variables-not only including the electrical charge balance and conservation of mass, but also the equilibria among bicarbonate ion formation, carbonate ion formation, water dissociation, and weak acid dissociation. Thus, in summary, accumulation of lactate might result in an increase of extracellular acidification even if it strongly depends on different variables (Figure 1).

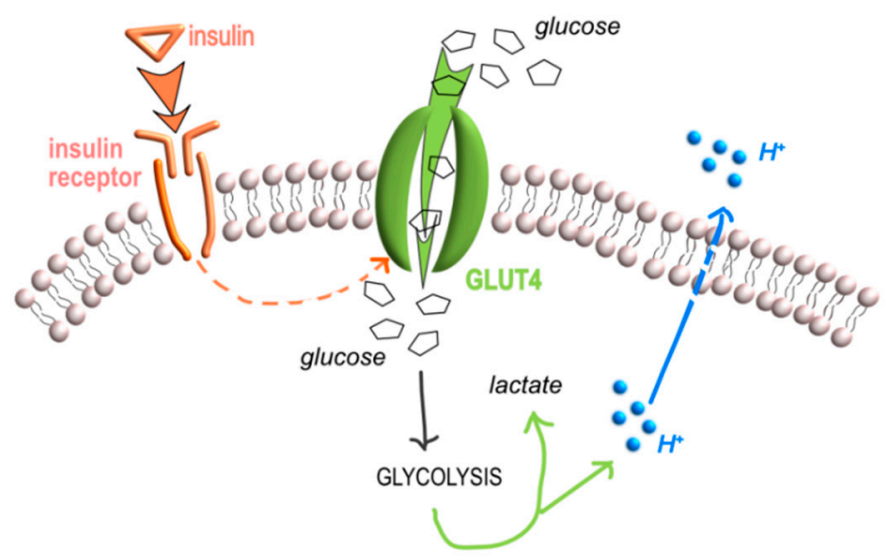

Figure 1. Insulin stimulation produces extracellular acidification. The insulin stimulated glucose uptake from the glucose transporters (GLUT) and glycolysis. Accumulation of lactate from glycolysis leads to a progressive increment of lactate and proton concentration. Protons are then transported across the cell membrane through several transporters, including monocarboxylate transporters (MCT), that also transport lactate to the extracellular space (orange arrow, the route of insulin; green allows, the route of the products of glycolysis, lactate and protons; blue arrow, the route of protons).

In addition, several proton transporters other than MCT can be used to promptly carry protons outside the cell. For more details, see different reviews available in this specific field $[4,15]$.

Regarding the impaired lactate metabolism and its role in hyperlactatemia-induced acidosis, lactate can by uptaken to be metabolized by various cells and tissues, such as liver, germ cells, and neurons, converting to pyruvate via LDH and subsequently serving as an energy source. In this case, lactate is uptaken mainly by the MCT1 isoform, thereby causing a final alkalinization effect [16]. Thus, a reduced lactate metabolism may indirectly cause acidification.

Finally, it should be considered that lactate exists as two optical isomers in nature: D-lactate and L-lactate [17]. L-lactate is by far the more abundant form in humans and mammals, existing at concentrations 100 times greater than D-lactate in blood. D-lactate can be metabolized by human cells, although at a much lower level than L-lactate since it is mainly metabolized by the bacteria of the gut microbiota. To date, it is not very clear whether the hyperlactatemia in diabetic patients is due to the increased concentration of L-lactate and D-lactate, and whether lactate acidosis is mainly due to the high concentration of D-lactate in the blood, rather than to L-lactate $[18,19]$.

Going back to the association between glycolysis and acidosis, based on Warburg's findings [20], direct evidence of a correlation between glycolysis and extracellular acidosis in cancer has been produced by combining magnetic resonance imaging, through coupling ${ }^{18} \mathrm{~F}$-fluoro-2-deoxy-D-glucose $\left.\left({ }^{18} \mathrm{~F}\right] \mathrm{FDG}\right)$ positron emission tomography (PET) and acido chemical exchange saturation transfer magnetic resonance imaging (acidoCEST MRI) [21,22]. These studies have demonstrated a significant inverse correlation between extracellular tumor $\mathrm{pH}$ and $\left[{ }^{18} \mathrm{~F}\right] \mathrm{FDG}$ uptake.

In conclusion, at least at the cell level, insulin binding to IR and the following activation of glycolysis might be a direct cause of interstitial acidification. 


\section{Acidosis-Mediated Effects on Insulin Activity and Resistance}

\subsection{Effects of Acidosis on Insulin Sensitivity and Release}

$\mathrm{pH}$ is known to modify insulin activity, and that acidification is considered as a mechanism of insulin resistance. By using in vivo models, it was demonstrated that $\mathrm{pH}$ regulation modifies basal and glucose-stimulated insulin secretion since hyperglycemia induced by the glucose load decreases more rapidly in alkalotic than in normal rats [23,24]. Previously, metabolic ketoacidosis was considered as the main cause. This was due to the fact that, both in human diabetic patients with metabolic acidosis and in animal models of diabetes, insulin resistance and the lack of the induction of glucose uptake and glycolysis were accompanied by increased concentrations of ketone bodies in the blood flow [25], and because animal models of severe ketoacidosis develop insulin resistance [26]. In the late nineties, studies on human patients on hemodialysis showing insulin resistance demonstrated that alkalinizing treatment with oral sodium bicarbonate $\left(\mathrm{NaHCO}_{3}\right)$ significantly increased insulin sensitivity and secretion [27]. Finally, by using the euglycemic clamp technique, Reaich et al. further confirmed that $\mathrm{NaHCO}_{3}$ treatment of patients with metabolic acidosis from chronic renal failure significantly increased insulin sensitivity [28].

The cause-and-effect relationship between changes in $\mathrm{pH}$ environments and alterations in insulin activity is still piecing. This is possibly due to the several variables that make the picture increasingly more complex. One possible cause of acidosis-induced insulin resistance has been demonstrated in transformed cells. Exposure to low $\mathrm{pH}$ directly reduces glycolysis, both after acute $[29,30]$ or chronic exposure [31]. In the latter case, glycolysis reduction is obtained through a switch to glutamine metabolism and is mediated by a nicotinammide adenina dinucleotide (NAD)(+)-dependent increase in sirtuin 1 (SIRT-1) deacetylase activity that deacetylates hypoxia-inducible factor (HIF) proteins to adapt to the acidic environment [31] (Figure 2a).

In addition, as demonstrated in human breast cancer Bcap37 cells, an acid $\mathrm{pH}$ may decrease glucose uptake and the glycolytic flux by directly inhibiting the activities of most glycolytic enzymes, including hexokinase (HK), aldolase, pyruvate kinase (PK), and LDH, with particular reference to phosphoglucose isomerase (PGI), phosphofructokinase (PFK), triosephosphate isomerase (TPI), and enolase, and through a mechanism that is independent of the presence of lactic acid [32]. Furthermore, incubation with an acid medium may down-regulate glycolysis also in normal cells. As an example, in mesenchymal stromal cells (MSC), exposure to an acid medium (6.6-6.7) changes the cellular metabolic profile since the expression of glucose transporters is significantly reduced and the ratio between MCT1 and MCT4 is up-regulated [33]. MCT1 mediates lactate uptake. Conversely, MCT4 facilitates the release of lactate into the extracellular environment, and both MCT1 and MCT4 are expressed both from normal and cancer cells [15,34,35]. In acid-loaded MSC, high levels of MCT1 increase lactate upload, whereas inhibition of GLUT1 and GLUT3 reduces glucose uptake, implying that under this stress condition MSC switch from glycolysis to OxPhos. This metabolic switch is also confirmed by a reduced expression of lactate dehydrogenase A (LDH-A) and pyruvate kinase isozymes $\mathrm{m} 2$ (PKM2) [33]. According to these data, it is possible to speculate that, at the individual cell level, cytosolic $\mathrm{pH}$ controls the glycolytic rate through a feedback mechanism because of the need to reduce the production of protons from glycolysis and thereby indirectly causing insulin resistance.

Finally, at a systemic level, it is known that acidification of the extracellular fluids stimulates the release of TGF- $\beta$ in normal cells, since either in MSC, in proximal tubular cells, or in hippocampal cultures, in comparison to normal conditions, acidosis causes a fourfold increase of the level of expression of TGF- $\beta$ or of TGF- $\beta 1$ bioactivity $[33,36,37]$ (Figure $2 b$ ). In turn, the systemic release of TGF- $\beta$ modulates pancreatic development and islet homeostasis and function as TGF- $\beta$ inhibits the replication of $\beta$-cells [38-40]. These data indirectly suggest that the acid-induced systemic release of TGF- $\beta$ might decrease the circulating level of insulin, thereby partially contributing to the feedback inhibitory mechanism of acidosis that ultimately results in insulin resistance. 


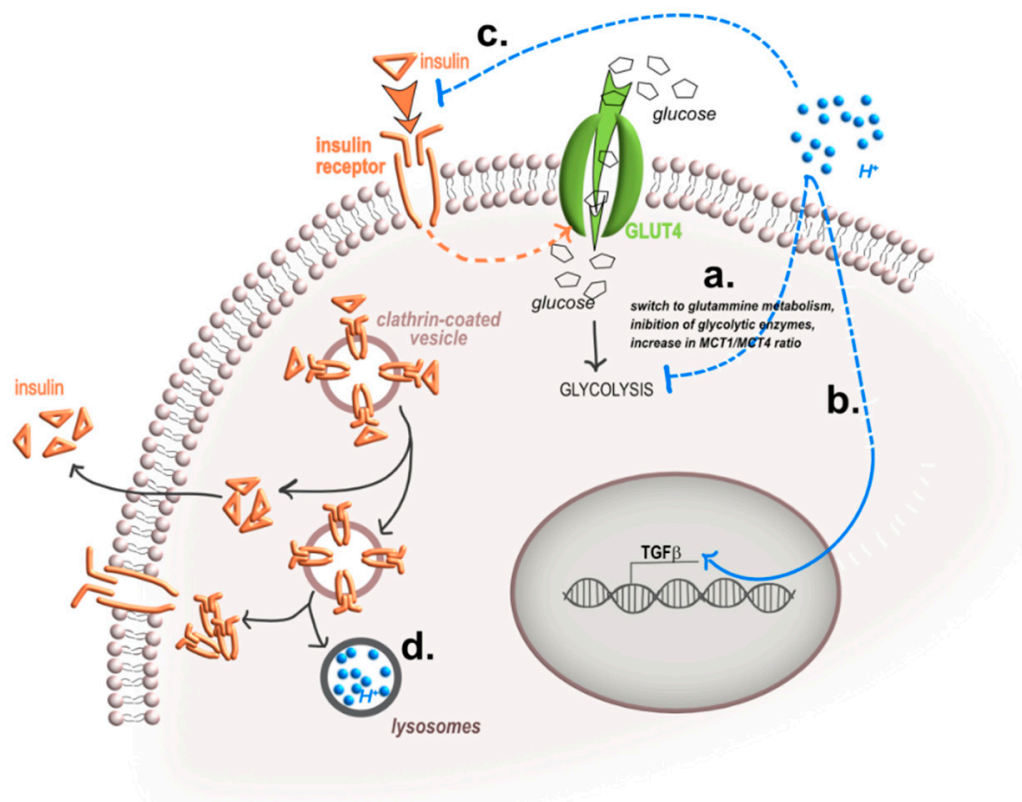

Figure 2. Effects of acidosis on insulin sensitivity and release. Low extracellular $\mathrm{pH}$ may interfere with insulin sensitivity and release in different ways. (a) Acidosis switches the cellular metabolism from glycolysis to other metabolic pathways, like glutamine metabolism via the Sirtuin 1 (SIRT-1) deacetylase activity that deacetylates hypoxia-inducible factor (HIF) proteins, or via the inhibition of the expression of glycolytic enzymes or through the increase of monocarboxylate transporter MCT1/MCT4 pathway; (b) acidosis induces the transcription and the protein expression of TGF- $\beta$ that, in turn, inhibits insulin release at the systemic level; (c) acidosis reduces at least $40 \%$ the binding affinity between insulin and IR; (d) acidosis interferes with the recycling process of both IR and insulin, by modifying the lysosome intraluminal $\mathrm{pH}$ and the number of lysosomes (blue arrow, the route of protons, black arrows, the route of insulin/IR complexes; T-bar, inhibition).

\subsection{Effects of Acidosis on Insulin Receptor Expression, Activation, and Signaling}

Acid-induced insulin resistance has been observed in several cell types [25,41-43]. A possible very simple reason for this effect is reduced insulin binding to its receptor at high proton concentrations (Figure 2c). Igarashi et al. have elegantly shown that in adipocytes, lowering of extracellular $\mathrm{pH}$ is associated with a reduced insulin binding rate (up to 70\%) [25]. In this experimental set, the authors demonstrated that such an effect was mainly due to a reduction in insulin binding affinity to its binding sites, without affecting the number of IR per cell. A reduced insulin binding rate at low $\mathrm{pH}$, compared to neutral $\mathrm{pH}$, has also been demonstrated in fibroblasts, erythrocytes, and myoblasts [41-46]. In particular, in L6 myoblasts, the insulin binding to IR was down-regulated up to $50 \%$ at $\mathrm{pH} 6.8$ [42]. Acidosis thus has the potential to directly affect the insulin-stimulated glucose uptake by interfering with the first step of the insulin signaling pathway, the IR activation, which, as a consequence, might impair the downstream IR signaling. Insulin stimulates glucose uptake mainly in a phosphatidylinositol 3-kinase (PI3K)-dependent pathway. After binding to IR, the autophosphorylation of IR and of the second messenger insulin receptor substrate-1 (IRS-1) leads to the activation of PI3K and the downstream Akt-mediated signaling. As a confirmation of this hypothesis, in rat myoblasts, a low $\mathrm{pH}$ (6.8) significantly affected the $100 \mathrm{nM}$ insulin stimulation of Tyr1146, Ser473, and Thr308 phosphorylation of IR. On the contrary, the expression of IR was not affected [42]. By using radiolabeled insulin, the same authors also demonstrated that the reduced IR phosphorylation was due to decreased insulin binding affinity to the receptor that was inversely correlated to the level of $\mathrm{pH}$ [42]. Notably, extracellular acidosis might also directly interfere with MEK/ERK (mitogen-activated protein kinases/extracellular signal-regulated kinases) signaling and Akt activation, regardless of insulin stimulation [4]. 
Finally, the level of expression of IR at the plasma membrane is strongly dependent on receptor recycling and lysosomal activity. Receptor-mediated endocytosis is an essential mechanism for several important physiological processes, and similarly to other receptor tyrosine kinases, IR undergoes ligand-induced internalization. After internalization, IR can be recycled to the cell surface, or can also undergo lysosomal degradation [9]. This event requires a specific amino-acid motif located at the intracellular part of the IR juxtamembrane domain. This motif targets the receptor to clathrin-coated pits, and from there to lysosomes, where the level of acid $\mathrm{pH}$ is thought to enhance insulin release [47]. In many cell types, insulin itself stimulates receptor endocytosis and accelerates the rate of receptor degradation. This process, called down-regulation, results in a decrease in the number of cell surface receptors and may be important to reduce signals initiated by insulin binding [48]. Whether this is a mechanism of insulin resistance is still controversial. However, it is proven than continuous exposure to high insulin levels induces subtle derangements of intracellular receptor trafficking and insulin degradation, and these alterations may contribute to insulin resistance of hyperinsulinemic states, such as obesity and Type 2 diabetes [49]. The lysosomal activity that regulates the internal trafficking of IR, as well as of insulin, might be affected by a reduced extracellular $\mathrm{pH}$ value. As an example, in breast cancer cells, rhabdomyosarcoma cells, and osteosarcoma cells, incubation with an acid medium increased the lysosomal diameter and decreased the luminal $\mathrm{pH}$ [50-52]. Thus, changes in the extracellular $\mathrm{pH}$ that are accompanied by changes in the intracellular $\mathrm{pH}$ and in lysosomal $\mathrm{pH}$ might be a critical factor for insulin secretion and insulin resistance (Figure 2d).

\subsection{Effect of Acidosis on the Expression of GLUT Transporters}

Insulin increases energy storage or utilization mainly through the regulation of the uptake of glucose by inducing the expression on the cell membrane of the GLUT4 transporter [53]. In patients with type 2 diabetes, the expression levels of GLUT4 in skeletal muscles are significantly decreased, resulting in a decreased glucose-processing ability. More rarely, GLUT1 has also been associated with insulin-mediated glycolysis regulation [54]. In more detail, insulin-induced glucose uptake is heavily regulated by the translocation of GLUT transporters to the cell membrane and the lasting of GLUT4 expression at this site. As for the IR, GLUT4 is continuously recycled and relocated between the plasma membrane and the intracellular compartment [53]. GLUT4 recycling is the result of consecutive and tightly regulated steps, including endocytosis, sorting into specialized vesicles, exocytosis, tethering, and fusion of the protein. In the absence of insulin, GLUT4 slowly recycles between the plasma membrane and vesicular compartments within the cell, where most of GLUT4 resides. Conversely, insulin stimulates the translocation of a pool of GLUT4 to the plasma membrane through a process of target endocytosis, where GLUT4 endocytosis is simultaneously attenuated [7]. The whole phenomenon involves signal transduction from the IR, vesicle trafficking (sorting and fusion processes), and actin cytoskeleton modifications, which are all supposed to require small guanosintrifosfato hydrolases (GTPases). In particular, various members of the Ras, Rad, Rho, Arf, and Rab families regulate the traffic of the GLUT4-containing vesicles [55], like Rab4b in adipocytes [56]. Also, Rab11 has been associated with GLUT4-containing vesicles' redistribution in response to insulin $[57,58]$. As discussed for IR, changes of extracellular $\mathrm{pH}$ might regulate the activity of endosomal vesicles, thereby determining the extent of GLUT4 re-localization and recycling. Actually, in HSG cells, extracellular acidosis up-regulated Rab11b expression and protein abundance and caused, as an example, the translocation of the vacuolar proton pump V-ATPase from intracellular pools toward the plasma membrane [59]. To date, it is not known how lowering the $\mathrm{pH}$ modulates small GTPases expression and their activity in determining GLUT recycling. It is demonstrated, however, at least in MSC, that the incubation with an acid medium promotes the down-regulation of the expression of GLUT1 and GLUT3 [33]. However, this hypothesis deserves further investigation. 


\section{Intracellular $\mathrm{pH}$ Regulation by Proton/Ion Transporters and Insulin Secretion}

To avoid the death-inducing stimulus of a high intracellular accumulation of protons that can be derived both from a reduction of extracellular $\mathrm{pH}$ or an increase of glycolysis, cells express different proton flux regulators at different extents, depending on the tissue of origin [15]. These pump/transport extrude protons out of the cytosol to maintain the cytosolic $\mathrm{pH}$. Among these, V-ATPase is widely expressed at the lysosomal membrane, whereas $\mathrm{Na}^{+} / \mathrm{H}^{+}$exchangers (NHE), MCT, and carbonic anhydrases (CA) are expressed at the cytoplasmic membrane [60-62]. The activity of these transporters/pumps have the net effect to reduce the luminal lysosomal $\mathrm{pH}$ and the $\mathrm{pH}$ of the extracellular space $[4,15]$. As these transporters are activated, intracellular $\mathrm{pH}(\mathrm{pHi})$ rises, albeit temporarily. However, chronic exposure to an excess of protons produces a paradoxical gradual and sustained increase of pHi. One of the most common examples for the constant rise of $\mathrm{pHi}$ in concert with chronic extracellular acidosis is cancer [63].

The rise of $\mathrm{pHi}$ is widely known as a critical factor for insulin secretion. One of the most studied models in this context are pancreatic $\beta$-cells. Glucose load in these cells, at concentrations above $3-5 \mathrm{mM}$, induces cellular depolarization and pHi transitory increments (up to 6.4-6.8 values) that directly stimulates insulin secretion [64-66]. Furthermore, Nabe et al. have demonstrated that diphenylhydantoin, a drug used for the treatment of epileptic patients, inhibits glucose-induced insulin release from pancreatic islets by decreasing intracellular proton concentration [67].

Although such a mechanism has not been fully elucidated, the increase of pHi after glucose loading in $\beta$-cells seems to be based on the presence of extracellular $\mathrm{Na}^{+}$and on the activity of sodium-hydrogen exchangers (NHE), since it is inhibited by 5 -(N-ethyl- $N$-isopropyl) amiloride, an NHE inhibitor $[65,66]$. According to these data, it is reasonable to speculate that the rise of $\mathrm{pHi}$ after glucose uptake is due to the activity of the $\mathrm{NHE} \mathrm{Na}{ }^{+} / \mathrm{H}^{+}$antiporter that counteracts the glycolysis-induced intracellular acidification (Figure 3A).

A similar phenomenon has also been observed in muscle cells. At $37^{\circ} \mathrm{C}$, acute exposure to insulin $\left(10^{-7} \mathrm{M}\right)$ and the resulting increase in glucose uptake produced an increase of $\mathrm{pHi}$ of 0.11 units in $10 \mathrm{~min}$. This increase became apparent $2 \mathrm{~min}$ after the addition of the hormone, and maximal elevation of $\mathrm{pHi}$ was observed after $10 \mathrm{~min}$, remaining elevated for up to $60 \mathrm{~min}$ [68]. In this case, pHi alkalinization was also prevented by amiloride. However, a recent review that summarized the most recent results on NHE and insulin clarified that plasmalemmal full-length NHE1 defends $\beta$-cells from intracellular acidification, but has no role in stimulus-secretion coupling and is not causally involved in glucose-induced alkalinization of the $\beta$-cell [69]. The discrepancy of the data reported in the literature so far on the relationship between the alkalinization activity of NHE and the stimulatory effect of a pHi rise on insulin secretion suggests the need to better clarify the phenomenon.

NHE also contributes to pHi regulation in arterial endothelial and smooth muscle cells and might thereby strongly influence blood pressure. In this respect, it is interesting to note that hypertensive patients often develop insulin resistance and hyperinsulinemia [70]. This is a chronic condition that may cause a paradoxical opposite effect in respect to those represented in Figure 3A. By using human red blood cells from patients with essential hypertension compared to red blood cells from normotensive subjects, it appeared that hypertensive patients had elevated basal NHE activity but a blunted response to insulin [71]. In this setting, a negative feedback mechanism might be suggested to prevent supplementary uptake of glucose that, after chronic exposure to insulin, would excessively acidify the cytosol (Figure 3B).

As for NHE, CA activity and its regulation of pHi might be involved in the altered metabolism of chronic hypertensive patients. CA is a well-characterized, $\mathrm{pH}$ regulatory, zinc-containing enzyme in most of the tissues in the body that catalyzes the reversible hydration of carbon dioxide: $\mathrm{CO}_{2}+\mathrm{H}_{2} \mathrm{O}<->\mathrm{HCO}_{3}{ }^{-}+\mathrm{H}^{+}$. Changes in $\mathrm{CA}$ activities have already been associated with cancer-altered metabolism [15]. By using p-nitrophenyl acetate as a substrate and acetazolamide, a CA9-specific inhibitor, in erythrocytes from normotensive and essential hypertensive subjects, Parui et al. demonstrated that two different levels of CA activities could be detected in these patients. 
One group showed much lower CA activity (mean $\pm \mathrm{SD}, 0.88 \pm 0.19 \mathrm{U} / \mathrm{min} / \mathrm{mL}$ ), whereas the other group showed higher $\mathrm{CA}$ activity (mean $\pm \mathrm{SD}, 1.77 \pm 0.23 \mathrm{U} / \mathrm{min} / \mathrm{mL}$ ) than normotensive controls (mean $\pm 1 \mathrm{SD}, 1.41 \pm 0.1 \mathrm{U} / \mathrm{min} / \mathrm{mL}$ ), and concluded that essential hypertensive patients were associated with altered CA activity [72]. Although the role of CA activity and other transporters that might modulate $\mathrm{pHi}$ in insulin sensitivity remains largely unexplained, these data altogether pave for pharmacological manipulations of $\mathrm{pHi}$ to treat insulin resistance.
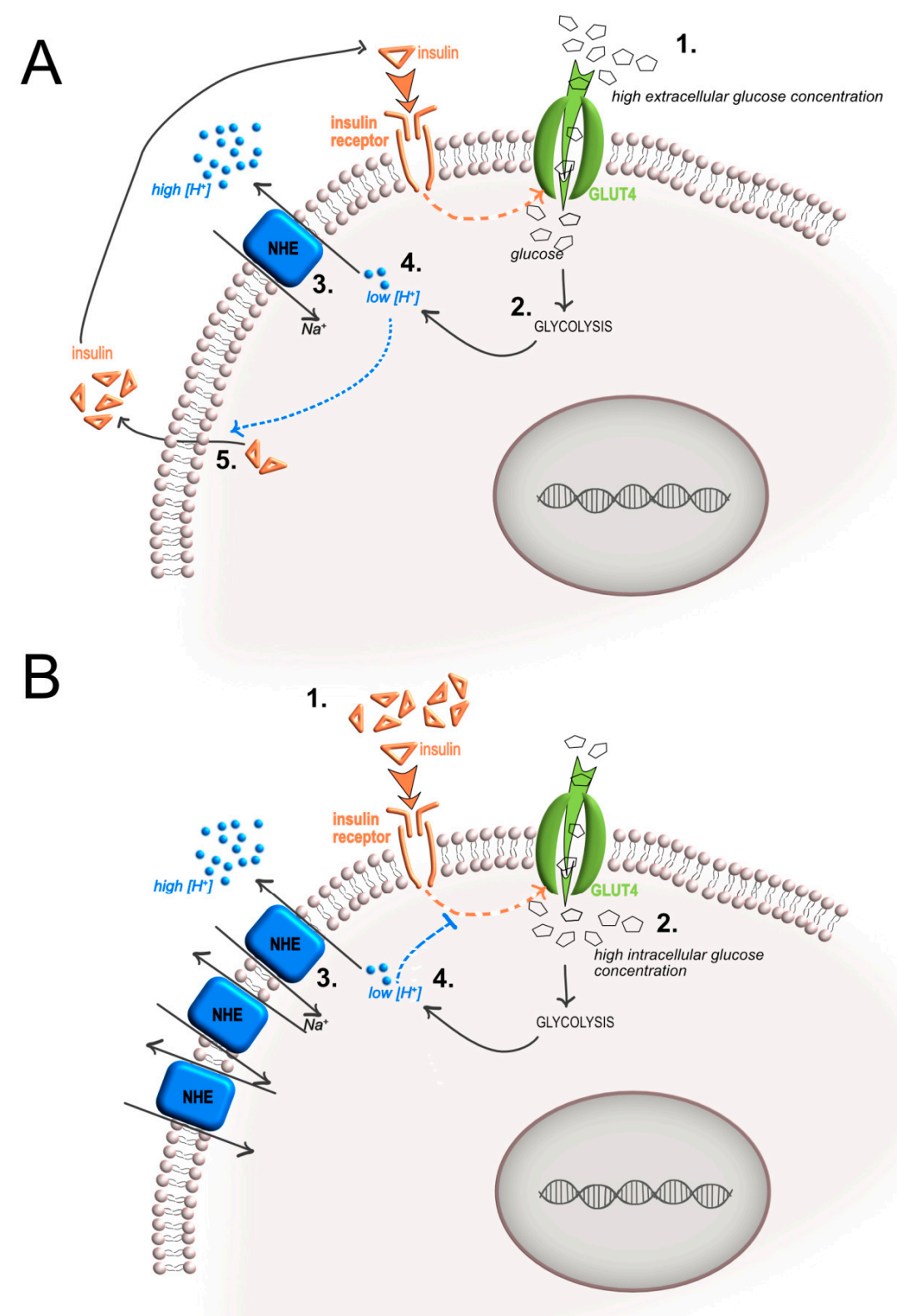

Figure 3. Intracellular $\mathrm{pH}$ regulation by NHE transporter, and insulin secretion and sensitivity. (A) A rise in intracellular $\mathrm{pH}(\mathrm{pHi})$ after glucose uptake is due to the activity of the $\mathrm{NHE} \mathrm{Na}^{+} / \mathrm{H}^{+}$ antiporter that is counteracting the glycolysis-induced intracellular acidification. The increase of $\mathrm{pHi}$ then directly stimulates insulin release; (B) in chronic hyperglycemia, a negative feedback mechanism may prevent supplementary uptake of glucose that, after chronic exposure to insulin, would excessively acidify the cytosol. This mechanism might cause a paradoxical effect mediated by a high level of NHE expression, thereby reducing insulin sensitivity (orange arrow, the route of insulin; blue arrow, the route of protons; T-bar, inhibition). 


\section{Insulin Receptors and Sensing Extracellular Acidosis}

Insulin-stimulated glucose uptake and glycolysis are reduced at low extracellular $\mathrm{pH}$, whereas insulin secretion is enhanced when pHi rises. It is then possible to speculate that specific mechanisms of sensing $\mathrm{pH}$ variation and gradient between the extracellular and the intracellular spaces exist, accounting for the activation of the insulin pathway and metabolic activity. Several extracellular proton-sensing mechanisms are expressed on cell membranes in many biological systems. The existence and the apparent redundancy of multiple $\mathrm{pH}$ surveillance systems attest to the concept that acid-base regulation is vital for cell and tissue homeostasis [73]. Indeed, in addition to carrying the multiple currents evoked by protons, these acid-sensing ion channels play fundamental roles in cell signaling and allow the host cell to respond to benign or harmful environmental changes [74,75]. There are at least two types of proton-sensing mechanisms, which sense variations of the extracellular proton concentration and transduce their signal inside the cells: acid-sensing ion channels (ASICS) and transient receptor potential vanilloid (TRPV) ion channels. ASICS and TRPV can detect a broad range of physiological $\mathrm{pH}$ changes, especially during pathological and synaptic cellular activities in neurons. Emerging evidence indicates that many of the acid-sensitive ion channels and receptors also play a role in the acid-evoked feedback regulation of homeostatic reactions, and can be expressed from cells other than neurons. As an example, ASICs have been detected in cells of the mesenchymal lineage [76], and with particular regard to ASIC3, knockout mice are protected against age-dependent glucose tolerance with enhanced insulin sensitivity [77]. By using the TRPV inhibitor capsaicin or TRPV knock-out mice, several types of TRPV have been revealed to contribute to cell function in pancreatic $\beta$-cells, including glucose metabolism and insulin secretion [78].

In addition to ionotropic ion channels, metabotropic proton-sensing $G$ protein-coupled receptors (GPCR) have been recently identified as a proton-sensing machinery. While ionotropic ion channels usually sense strong acidic $\mathrm{pH}$, proton-sensing GPCRs sense a $\mathrm{pH}$ of 7.6 to 6.0 and mediate a variety of biological actions under neutral and mildly acidic $\mathrm{pH}$ environments [79]. Referring to ovarian cancer, in addition to ASIC3, the proton-sensing GPCR G protein-coupled receptor 1 (OGR1) has been proven to function in physiological events, such as insulin secretion and/or normal glucose metabolism. OGR1 is activated by neutral or mildly acidic $\mathrm{pH}(\mathrm{pH}$ 7.4 7.0) and stimulates the processes of the KATP channel and/or VDCC, and thereby enhances glucose-stimulated insulin secretion through the phospholipase $\mathrm{C}$ (PLC) $/ \mathrm{Ca}^{2+}$ signaling pathways [79]. Finally, in normal pancreatic $\beta$-cells, OGR1 agonists (small molecule 3,5-disubstituted isoxazoles) stimulate insulin synthesis [79].

In conclusion, current fragmentary data suggest that a fine-tuning of insulin activity and sensitivity is under the control of $\mathrm{pH}$ surveillance systems, a concept that might strongly impact on our understanding of the regulation of glucose homeostasis. However, the role of proton-sensing receptors in insulin sensitivity and release is still unclear and deserves further investigation.

\section{Insulin Receptor-Induced Inflammatory Pathway and Acidosis}

Tissue acidification ( $\mathrm{pH}$ decrease of at least $0.5-1.0 \mathrm{pH}$ unit) is commonly associated with inflammation [80]. Indeed, after sensing the extracellular $\mathrm{pH}$ changes, ASICs might initiate an inflammatory response [75]. As an example, lowering $\mathrm{pH}$ promotes the expression of the mRNA messenger of IL-6, and IL-8, as well as of NF-kB1, RelA, and RelB already after $3 \mathrm{~h}$ from the exposure to acidosis ( $\mathrm{pH}$ 6.8), and after $24 \mathrm{~h}$, it promotes the intranuclear protein expression of members of the NF- $\mathrm{kB}$ family and the release of the inflammatory cytokines IL- 6 and IL-8, both in human MSC and osteoblasts [76,81]. Similarly, GPCRs that can sense the acid stimulus can mediate inflammatory and related responses, like for T-cell death-associated gene 8 (TDAG8, also known as GPR65), that enhances the production of IL-6, TNF- $\alpha$, and IL-1 $\beta$ in the infarcted hearts of mouse models [82].

Activation of inflammatory pathways by acidosis can, in turn, impair glucose metabolism and cause systemic insulin resistance. Lipid-induced insulin resistance has been associated with inflammation in epidemiological studies, and by means of different models, several authors have demonstrated that induction of NF-KB activation reduces net insulin-stimulated glucose uptake. 
For an extensive review, see Reference [83]. In particular, Chang et al. have shown that in $\mathrm{C} 2 \mathrm{C} 12$ myotubes, transfection with siRNA against the NF- $\mathrm{kB}$ member, the nuclear factor of kappa light polypeptide gene enhancer in B-cells inhibitor alpha insulin receptor substrate 1 (I $\kappa \mathrm{B} \alpha$ ), for $24 \mathrm{~h}$ leads to a twofold induction of NF- $\mathrm{kB}$ activation, reduced net insulin-stimulated glucose uptake by $30 \%$, GLUT4 translocation by 35\%, Akt phosphorylation by 31\%, and a 0.7 -fold increase in insulin-stimulated insulin receptor substrate 1 (IRS-1) phosphorylation [84]. The enhancement of GLUT4 expression via NF- $\mathrm{KB}$ has also been confirmed in other models [85]. Furthermore, other authors have demonstrated in adipocytes that the IKB kinase $\beta$ (IKK $\beta$ ), c-Jun N-terminal kinase (JNK), and S6K and mTOR32 kinases carry out inhibitory phosphorylation of IRS-1, thus causing insulin resistance [9]. Both experimental and clinical studies now converge to show that several ILs contribute to the pathology and physiology of Type 2 diabetes through their interaction with insulin signaling pathways and $\beta$-cell functions. Notably, IL-1, which is a major proinflammatory cytokine, is present at increased levels in patients with diabetes mellitus, and could promote $\beta$-cell destruction and alter insulin sensitivity [86]. Likewise, IL-6 has been suggested to be involved in the development of obesity-related and diabetes mellitus Type 2-related insulin resistance. The action of IL-6 on glucose homeostasis is also complex, and integrates central and peripheral mechanisms [87]. Overall, these data demonstrate that acidosis has the potential to indirectly cause insulin resistance via the activation of NF- $\mathrm{KB}$ pathways and the release of inflammatory cytokines, an already well-known cause of chronic inflammation in diabetic patients.

\section{Conclusions}

Acidosis modulates insulin sensitivity and resistance in many different and complex ways. Notably, the timing of exposure to acidosis is a crucial factor in this context, since acute and chronic effects of acidosis may have completely opposite effects. To control acid-related diseases, several approaches have been suggested in mouse models, including the use of bicarbonate $[4,88]$. Once translated to the clinical practice, however, results obtained from these studies might produce quite uncertain and dangerous effects in humans. For diseases associated with insulin resistance, like for type 2 diabetes, decreasing dietary acid load may be an achievable alternative and a relevant route to improve glucose homeostasis and prevention on a long-term basis. However, limitations related to patient acid load estimation, nutritional determinants, and metabolic status considerably flaws available findings, and the lack of solid data on the background pathophysiology contributes to the questionability of results. Furthermore, evidence from interventional studies is very limited and the trials carried out so far report no beneficial results following alkali supplementation [89]. Nevertheless, the relation between insulin metabolism and the regulation of $\mathrm{pH}$ is an exciting and fascinating field of investigation for the identification of novel therapeutic approaches. Furthermore, in clinical practice, data that have been collected so far suggest considering $\mathrm{pH}$ not only as a body parameter to be continuously kept under control to avoid the dangerous effects of systemic acidosis or alkalosis, but also as a main driver that directly modulates crucial biological processes, either at the systemic, cellular, or molecular level.

Funding: This research was funded by the Italian Association for Cancer Research [grant n. 15608 to N.B.], and the financial support for Scientific Research "5 per mille 2015" (to N.B.).

Conflicts of Interest: The authors declare no conflict of interest. The funders had no role in the design of the study and in the writing of the manuscript.

\section{Abbreviations}

acidoCEST MRI

AIDS

ASICS

CA

$\left[{ }^{18}\right.$ F]FDG PET

GLUT

acido chemical exchange saturation transfer magnetic resonance imaging acquired immunodeficiency syndrome

acid-sensing ion channels

carbonic anhydrases

${ }^{18}$ F-fluoro-2-deoxy-D-glucose positron emission tomography

glucose transporters 


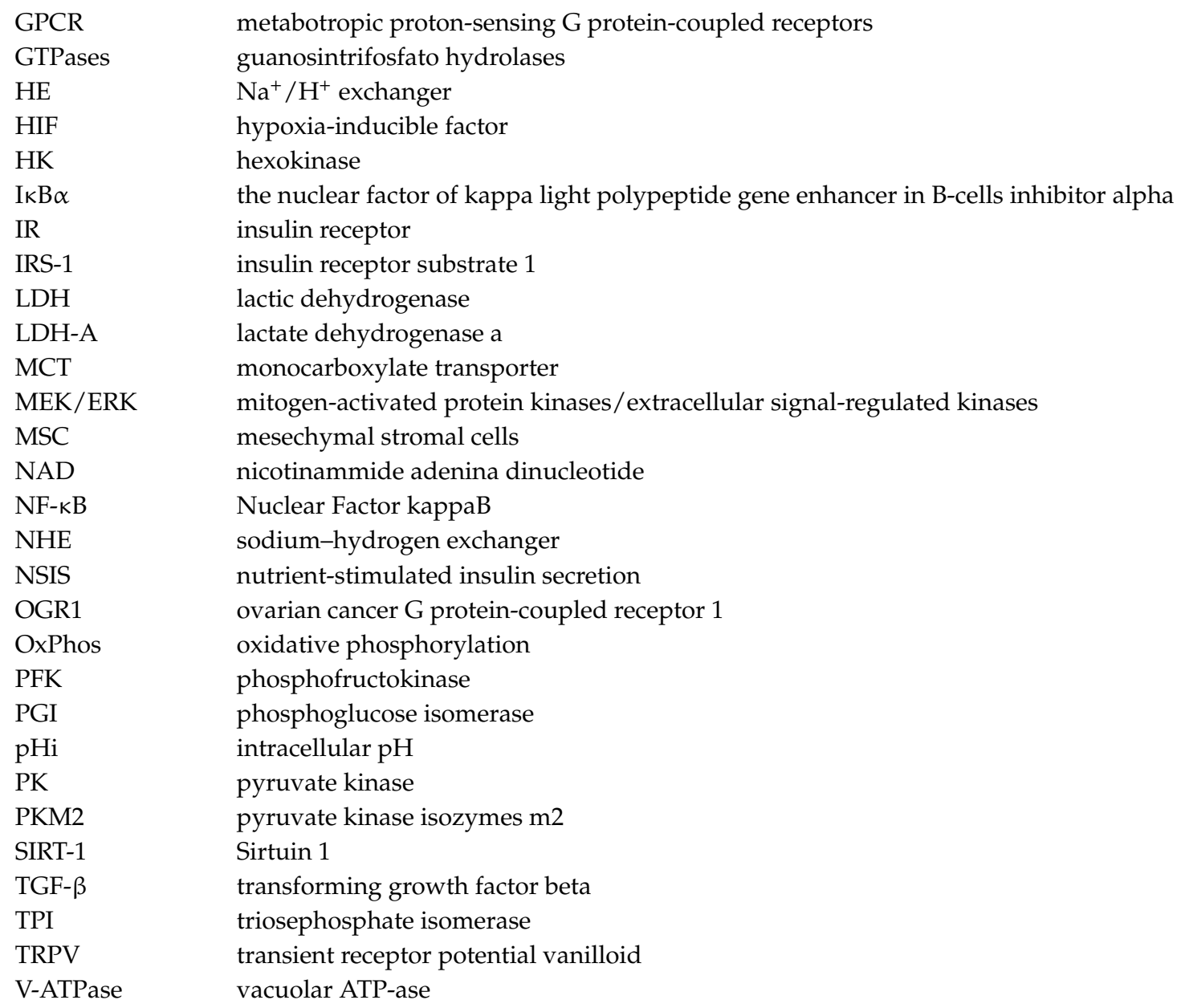

\section{References}

1. Arnett, T. Regulation of bone cell function by acid-base balance. Proc. Nutr. Soc. 2003, 62, 511-520. [CrossRef] [PubMed]

2. Ratel, S.; Duche, P.; Hennegrave, A.; Van Praagh, E.; Bedu, M. Acid-base balance during repeated cycling sprints in boys and men. J. Appl. Physiol. (1985) 2002, 92, 479-485. [CrossRef] [PubMed]

3. Frassetto, L.A.; Morris, R.C., Jr.; Sebastian, A. Effect of age on blood acid-base composition in adult humans: Role of age-related renal functional decline. Am. J. Physiol. 1996, 271, F1114-F1122. [CrossRef] [PubMed]

4. Kolosenko, I.; Avnet, S.; Baldini, N.; Viklund, J.; De Milito, A. Therapeutic implications of tumor interstitial acidification. Semin. Cancer Biol. 2017, 43, 119-133. [CrossRef] [PubMed]

5. Massa, A.; Perut, F.; Chano, T.; Woloszyk, A.; Mitsiadis, T.A.; Avnet, S.; Baldini, N. The effect of extracellular acidosis on the behaviour of mesenchymal stem cells in vitro. Eur. Cell. Mater. 2017, 33, 252-267. [CrossRef] [PubMed]

6. Marunaka, Y.; Yoshimoto, K.; Aoi, W.; Hosogi, S.; Ikegaya, H. Low pH of interstitial fluid around hippocampus of the brain in diabetic OLETF rats. Mol. Cell. Ther. 2014, 2, 6. [CrossRef] [PubMed]

7. Chang, L.; Chiang, S.H.; Saltiel, A.R. Insulin signaling and the regulation of glucose transport. Mol. Med. 2004, 10, 65-71. [PubMed]

8. Goguen, J.M.; Halperin, M.L. Can insulin administration cause an acute metabolic acidosis in vivo? An experimental study in dogs. Diabetologia 1993, 36, 813-816. [CrossRef]

9. Haeusler, R.A.; McGraw, T.E.; Accili, D. Biochemical and cellular properties of insulin receptor signalling. Nat. Rev. Mol. Cell Biol. 2018, 19, 31-44. [CrossRef]

10. Adeva-Andany, M.; Lopez-Ojen, M.; Funcasta-Calderon, R.; Ameneiros-Rodriguez, E.; Donapetry-Garcia, C.; Vila-Altesor, M.; Rodriguez-Seijas, J. Comprehensive review on lactate metabolism in human health. Mitochondrion 2014, 17, 76-100. [CrossRef] 
11. Seheult, J.; Fitzpatrick, G.; Boran, G. Lactic acidosis: An update. Clin. Chem. Lab. Med. 2017, 55, $322-333$. [CrossRef]

12. Robergs, R.A.; Ghiasvand, F.; Parker, D. Biochemistry of exercise-induced metabolic acidosis. Am. J. Physiol. Regul. Integr. Comp. Physiol. 2004, 287, R502-R516. [CrossRef] [PubMed]

13. Corbet, C.; Feron, O. Tumour acidosis: From the passenger to the driver's seat. Nat. Rev. Cancer 2017, 17, 577-593. [CrossRef]

14. Halestrap, A.P.; Price, N.T. The proton-linked monocarboxylate transporter (MCT) family: Structure, function and regulation. Biochem. J. 1999, 343, 281-299. [CrossRef] [PubMed]

15. Spugnini, E.P.; Sonveaux, P.; Stock, C.; Perez-Sayans, M.; De Milito, A.; Avnet, S.; Garcia, A.G.; Harguindey, S.; Fais, S. Proton channels and exchangers in cancer. Biochim. Biophys. Acta 2015, 1848, 2715-2726. [CrossRef] [PubMed]

16. Naylor, J.M.; Kronfeld, D.S.; Freeman, D.E.; Richardson, D. Hepatic and extrahepatic lactate metabolism in sheep: Effects of lactate loading and pH. Am. J. Physiol. 1984, 247, E747-E755. [CrossRef] [PubMed]

17. Ewaschuk, J.B.; Naylor, J.M.; Zello, G.A. D-lactate in human and ruminant metabolism. J. Nutr. 2005, 135, 1619-1625. [CrossRef]

18. Claus, P.; Gimenes, A.M.; Castro, J.R.; Mantovani, M.M.; Kanayama, K.K.; Simoes, D.M.N.; Schwartz, D.S. Blood lactate concentration in diabetic dogs. Can. Vet. J. 2017, 58, 817-822.

19. Lu, J.; Zello, G.A.; Randell, E.; Adeli, K.; Krahn, J.; Meng, Q.H. Closing the anion gap: Contribution of D-lactate to diabetic ketoacidosis. Clin. Chim. Acta 2011, 412, 286-291. [CrossRef]

20. Warburg, O. On the origin of cancer cells. Science 1956, 123, 309-314. [CrossRef]

21. Goldenberg, J.M.; Cardenas-Rodriguez, J.; Pagel, M.D. Preliminary Results that Assess Metformin Treatment in a Preclinical Model of Pancreatic Cancer Using Simultaneous [(18)F]FDG PET and acidoCEST MRI. Mol. Imaging Biol. 2018, 20, 575-583. [CrossRef] [PubMed]

22. Longo, D.L.; Bartoli, A.; Consolino, L.; Bardini, P.; Arena, F.; Schwaiger, M.; Aime, S. In Vivo Imaging of Tumor Metabolism and Acidosis by Combining PET and MRI-CEST pH Imaging. Cancer Res. 2016, 76, 6463-6470. [CrossRef] [PubMed]

23. Yajima, M.; Ui, M. Carbohydrate metabolism and its response to catecholamines as modified in alkalotic rat. Am. J. Physiol. 1975, 228, 1046-1052. [CrossRef] [PubMed]

24. Uajima, M.; Ui, M. Hydrocortisone restoration of the $\mathrm{pH}$-dependent metabolic responses to catecholamines. Am. J. Physiol. 1975, 228, 1053-1059. [CrossRef] [PubMed]

25. Igarashi, M.; Yamatani, K.; Fukase, N.; Daimon, M.; Ohnuma, H.; Ogawa, A.; Tominaga, M.; Sasaki, H. Effect of acidosis on insulin binding and glucose uptake in isolated rat adipocytes. Tohoku J. Exp. Med. 1993, 169, 205-213. [CrossRef]

26. Cuthbert, C.; Alberti, K.G. Acidemia and insulin resistance in the diabetic ketoacidotic rat. Metabolism 1978, 27, 1903-1916. [CrossRef]

27. Mak, R.H. Effect of metabolic acidosis on insulin action and secretion in uremia. Kidney Int. 1998, 54, $603-607$. [CrossRef]

28. Reaich, D.; Graham, K.A.; Channon, S.M.; Hetherington, C.; Scrimgeour, C.M.; Wilkinson, R.; Goodship, T.H. Insulin-mediated changes in PD and glucose uptake after correction of acidosis in humans with CRF. Am. J. Physiol. 1995, 268, E121-E126. [CrossRef]

29. Chano, T.; Avnet, S.; Kusuzaki, K.; Bonuccelli, G.; Sonveaux, P.; Rotili, D.; Mai, A.; Baldini, N. Tumour-specific metabolic adaptation to acidosis is coupled to epigenetic stability in osteosarcoma cells. Am. J. Cancer Res. 2016, 6, 859-875.

30. Lamonte, G.; Tang, X.; Chen, J.L.; Wu, J.; Ding, C.K.; Keenan, M.M.; Sangokoya, C.; Kung, H.N.; Ilkayeva, O.; Boros, L.G.; et al. Acidosis induces reprogramming of cellular metabolism to mitigate oxidative stress. Cancer Metab. 2013, 1, 23. [CrossRef]

31. Corbet, C.; Draoui, N.; Polet, F.; Pinto, A.; Drozak, X.; Riant, O.; Feron, O. The SIRT1/HIF2alpha axis drives reductive glutamine metabolism under chronic acidosis and alters tumor response to therapy. Cancer Res. 2014, 74, 5507-5519. [CrossRef] [PubMed]

32. Xie, J.; Wu, H.; Dai, C.; Pan, Q.; Ding, Z.; Hu, D.; Ji, B.; Luo, Y.; Hu, X. Beyond Warburg effect-dual metabolic nature of cancer cells. Sci. Rep. 2014, 4, 4927. [CrossRef] [PubMed] 
33. Peppicelli, S.; Bianchini, F.; Toti, A.; Laurenzana, A.; Fibbi, G.; Calorini, L. Extracellular acidity strengthens mesenchymal stem cells to promote melanoma progression. Cell Cycle 2015, 14, 3088-3100. [CrossRef] [PubMed]

34. Lemma, S.; Di Pompo, G.; Porporato, P.E.; Sboarina, M.; Russell, S.; Gillies, R.J.; Baldini, N.; Sonveaux, P.; Avnet, S. MDA-MB-231 breast cancer cells fuel osteoclast metabolism and activity: A new rationale for the pathogenesis of osteolytic bone metastases. Biochim. Biophys. Acta Mol. Basis Dis. 2017, 1863, 3254-3264. [CrossRef] [PubMed]

35. Counillon, L.; Bouret, Y.; Marchiq, I.; Pouyssegur, J. $\mathrm{Na}(+) / \mathrm{H}(+)$ antiporter (NHE1) and lactate/H(+) symporters (MCTs) in pH homeostasis and cancer metabolism. Biochim. Biophys. Acta 2016, 1863, 2465-2480. [CrossRef] [PubMed]

36. Cabalgante, M.J.; Gadola, L.; Luzardo, L.; Marquez, M.; Boggia, J.; Boim, M.A. Calcium citrate improves the epithelial-to-mesenchymal transition induced by acidosis in proximal tubular cells. J. Bras. Nefrol. 2012, 34, 343-348. [CrossRef]

37. Uribe-San Martin, R.; Herrera-Molina, R.; Olavarria, L.; Ramirez, G.; von Bernhardi, R. Reduction of beta-amyloid-induced neurotoxicity on hippocampal cell cultures by moderate acidosis is mediated by transforming growth factor beta. Neuroscience 2009, 158, 1338-1347. [CrossRef]

38. Smart, N.G.; Apelqvist, A.A.; Gu, X.; Harmon, E.B.; Topper, J.N.; MacDonald, R.J.; Kim, S.K. Conditional expression of Smad7 in pancreatic beta cells disrupts TGF-beta signaling and induces reversible diabetes mellitus. PLoS Biol. 2006, 4, e39. [CrossRef]

39. Lin, H.M.; Lee, J.H.; Yadav, H.; Kamaraju, A.K.; Liu, E.; Zhigang, D.; Vieira, A.; Kim, S.J.; Collins, H.; Matschinsky, F; et al. Transforming growth factor-beta/Smad3 signaling regulates insulin gene transcription and pancreatic islet beta-cell function. J. Biol. Chem. 2009, 284, 12246-12257. [CrossRef]

40. Dhawan, S.; Dirice, E.; Kulkarni, R.N.; Bhushan, A. Inhibition of TGF-beta Signaling Promotes Human Pancreatic beta-Cell Replication. Diabetes 2016, 65, 1208-1218. [CrossRef]

41. Hidaka, H.; Howard, B.V.; Ishibashi, F.; Kosmakos, F.C.; Craig, J.W.; Bennett, P.H.; Larner, J. Effect of pH and 3-hydroxybutyrate on insulin binding and action in cultured human fibroblasts. Diabetes 1981, 30, 402-406. [CrossRef]

42. Hayata, H.; Miyazaki, H.; Niisato, N.; Yokoyama, N.; Marunaka, Y. Lowered extracellular pH is involved in the pathogenesis of skeletal muscle insulin resistance. Biochem. Biophys. Res. Commun. 2014, 445, 170-174. [CrossRef] [PubMed]

43. Whittaker, J.; Cuthbert, C.; Hammond, V.A.; Alberti, K.G. The effects of metabolic acidosis in vivo on insulin binding to isolated rat adipocytes. Metabolism 1982, 31, 553-557. [CrossRef]

44. Hara, H.; Hidaka, H.; Kosmakos, F.C.; Mott, D.M.; Vasquez, B.; Howard, B.V.; Bennett, P.H. Characterization of the human insulin receptor solubilized from cultured fibroblast and erythrocyte cell membrane preparations. J. Clin. Endocrinol. Metab. 1981, 52, 17-22. [CrossRef] [PubMed]

45. Van Putten, J.P.; Wieringa, T.; Krans, H.M. Low $\mathrm{pH}$ and ketoacids induce insulin receptor binding and postbinding alterations in cultured 3 T3 adipocytes. Diabetes 1985, 34, 744-750. [CrossRef] [PubMed]

46. Ohtsuka, H.; Yamauchi, K.; Ohara, N.; Miyamoto, T.; Ichikawa, K.; Hashizume, K. Effects of beta-hydroxy butyric acid on insulin binding to its receptor and on autophosphorylation of the receptor. Endocrinol. Jpn. 1990, 37, 915-922. [CrossRef] [PubMed]

47. Haft, C.R.; De La Luz Sierra, M.; Hamer, I.; Carpentier, J.L.; Taylor, S.I. Analysis of the juxtamembrane dileucine motif in the insulin receptor. Endocrinology 1998, 139, 1618-1629. [CrossRef]

48. Kasuga, M.; Kahn, C.R.; Hedo, J.A.; Van Obberghen, E.; Yamada, K.M. Insulin-induced receptor loss in cultured human lymphocytes is due to accelerated receptor degradation. Proc. Natl. Acad. Sci. USA 1981, 78, 6917-6921. [CrossRef]

49. Bertacca, A.; Ciccarone, A.; Cecchetti, P.; Vianello, B.; Laurenza, I.; Del Prato, S.; Benzi, L. High insulin levels impair intracellular receptor trafficking in human cultured myoblasts. Diabetes Res. Clin. Pract. 2007, 78, 316-323. [CrossRef]

50. Salerno, M.; Avnet, S.; Bonuccelli, G.; Hosogi, S.; Granchi, D.; Baldini, N. Impairment of lysosomal activity as a therapeutic modality targeting cancer stem cells of embryonal rhabdomyosarcoma cell line RD. PLoS ONE 2014, 9, e110340. [CrossRef] 
51. Avnet, S.; Lemma, S.; Cortini, M.; Pellegrini, P.; Perut, F.; Zini, N.; Kusuzaki, K.; Chano, T.; Grisendi, G.; Dominici, M.; et al. Altered $\mathrm{pH}$ gradient at the plasma membrane of osteosarcoma cells is a key mechanism of drug resistance. Oncotarget 2016, 7, 63408-63423. [CrossRef] [PubMed]

52. Glunde, K.; Guggino, S.E.; Solaiyappan, M.; Pathak, A.P.; Ichikawa, Y.; Bhujwalla, Z.M. Extracellular acidification alters lysosomal trafficking in human breast cancer cells. Neoplasia 2003, 5, 533-545. [CrossRef]

53. Huang, S.; Czech, M.P. The GLUT4 glucose transporter. Cell Metab. 2007, 5, 237-252. [CrossRef] [PubMed]

54. Taha, C.; Mitsumoto, Y.; Liu, Z.; Skolnik, E.Y.; Klip, A. The insulin-dependent biosynthesis of GLUT1 and GLUT3 glucose transporters in L6 muscle cells is mediated by distinct pathways. Roles of p21ras and pp70 S6 kinase. J. Biol. Chem. 1995, 270, 24678-24681. [CrossRef] [PubMed]

55. Cormont, M.; Le Marchand-Brustel, Y. The role of small G-proteins in the regulation of glucose transport (review). Mol. Membr. Biol. 2001, 18, 213-220. [CrossRef] [PubMed]

56. Kaddai, V.; Gonzalez, T.; Keslair, F.; Gremeaux, T.; Bonnafous, S.; Gugenheim, J.; Tran, A.; Gual, P.; Le Marchand-Brustel, Y.; Cormont, M. Rab4b is a small GTPase involved in the control of the glucose transporter GLUT4 localization in adipocyte. PLoS ONE 2009, 4, e5257. [CrossRef]

57. Kessler, A.; Tomas, E.; Immler, D.; Meyer, H.E.; Zorzano, A.; Eckel, J. Rab11 is associated with GLUT4-containing vesicles and redistributes in response to insulin. Diabetologia 2000, 43, 1518-1527. [CrossRef]

58. Uhlig, M.; Passlack, W.; Eckel, J. Functional role of Rab11 in GLUT4 trafficking in cardiomyocytes. Mol. Cell. Endocrinol. 2005, 235, 1-9. [CrossRef]

59. Oehlke, O.; Martin, H.W.; Osterberg, N.; Roussa, E. Rab11b and its effector Rip11 regulate the acidosis-induced traffic of V-ATPase in salivary ducts. J. Cell. Physiol. 2011, 226, 638-651. [CrossRef]

60. Supuran, C.T. Structure and function of carbonic anhydrases. Biochem. J. 2016, 473, 2023-2032. [CrossRef]

61. Iwanaga, T.; Kishimoto, A. Cellular distributions of monocarboxylate transporters: A review. Biomed. Res. 2015, 36, 279-301. [CrossRef] [PubMed]

62. Jones, R.S.; Morris, M.E. Monocarboxylate Transporters: Therapeutic Targets and Prognostic Factors in Disease. Clin. Pharmacol. Ther. 2016, 100, 454-463. [CrossRef] [PubMed]

63. Damaghi, M.; Wojtkowiak, J.W.; Gillies, R.J. pH sensing and regulation in cancer. Front. Physiol. 2013, 4, 370. [CrossRef] [PubMed]

64. Gunawardana, S.C.; Rocheleau, J.V.; Head, W.S.; Piston, D.W. Nutrient-stimulated insulin secretion in mouse islets is critically dependent on intracellular pH. BMC Endocr. Disord. 2004, 4, 1. [CrossRef] [PubMed]

65. Juntti-Berggren, L.; Arkhammar, P.; Nilsson, T.; Rorsman, P.; Berggren, P.O. Glucose-induced increase in cytoplasmic $\mathrm{pH}$ in pancreatic beta-cells is mediated by $\mathrm{Na}^{+} / \mathrm{H}^{+}$exchange, an effect not dependent on protein kinase C. J. Biol. Chem. 1991, 266, 23537-23541. [PubMed]

66. Best, L.; Bone, E.A.; Meats, J.E.; Tomlinson, S. Is intracellular pH a coupling factor in nutrient-stimulated pancreatic islets? J. Mol. Endocrinol. 1988, 1, 33-38. [CrossRef] [PubMed]

67. Nabe, K.; Fujimoto, S.; Shimodahira, M.; Kominato, R.; Nishi, Y.; Funakoshi, S.; Mukai, E.; Yamada, Y.; Seino, Y.; Inagaki, N. Diphenylhydantoin suppresses glucose-induced insulin release by decreasing cytoplasmic $\mathrm{H}^{+}$concentration in pancreatic islets. Endocrinology 2006, 147, 2717-2727. [CrossRef]

68. Klip, A.; Ramlal, T.; Cragoe, E.J., Jr. Insulin-induced cytoplasmic alkalinization and glucose transport in muscle cells. Am. J. Physiol. 1986, 250, C720-C728. [CrossRef]

69. Deisl, C.; Albano, G.; Fuster, D.G. Role of Na/H exchange in insulin secretion by islet cells. Curr. Opin. Nephrol. Hypertens. 2014, 23, 406-410. [CrossRef]

70. Ohishi, M. Hypertension with diabetes mellitus: Physiology and pathology. Hypertens. Res. 2018, 41, 389-393. [CrossRef]

71. Romero, J.R.; Rivera, A.; Conlin, P.R. Red blood cell $\mathrm{Na}^{+} / \mathrm{H}^{+}$exchange activity is insulin resistant in hypertensive patients. Clin. Exp. Hypertens. 2002, 24, 277-287. [CrossRef] [PubMed]

72. Parui, R.; Gambhir, K.K.; Mehrotra, P.P. Changes in carbonic anhydrase may be the initial step of altered metabolism in hypertension. Biochem. Int. 1991, 23, 779-789. [PubMed]

73. Holzer, P. Acid-sensitive ion channels and receptors. Handb. Exp. Pharmacol. 2009, 194, 283-332.

74. Zheng, J. Molecular mechanism of TRP channels. Compr. Physiol. 2013, 3, 221-242. [PubMed]

75. Cheng, Y.R.; Jiang, B.Y.; Chen, C.C. Acid-sensing ion channels: Dual function proteins for chemo-sensing and mechano-sensing. J. Biomed. Sci. 2018, 25, 46. [CrossRef] [PubMed] 
76. Avnet, S.; Di Pompo, G.; Chano, T.; Errani, C.; Ibrahim-Hashim, A.; Gillies, R.J.; Donati, D.M.; Baldini, N. Cancer-associated mesenchymal stroma fosters the stemness of osteosarcoma cells in response to intratumoral acidosis via NF-kappaB activation. Int. J. Cancer 2017, 140, 1331-1345. [CrossRef] [PubMed]

77. Huang, S.J.; Yang, W.S.; Lin, Y.W.; Wang, H.C.; Chen, C.C. Increase of insulin sensitivity and reversal of age-dependent glucose intolerance with inhibition of ASIC3. Biochem. Biophys. Res. Commun. 2008, 371, 729-734. [CrossRef]

78. Uchida, K.; Tominaga, M. The role of thermosensitive TRP (transient receptor potential) channels in insulin secretion. Endocr. J. 2011, 58, 1021-1028. [CrossRef]

79. Mogi, C.; Nakakura, T.; Okajima, F. Role of extracellular proton-sensing OGR1 in regulation of insulin secretion and pancreatic beta-cell functions. Endocr. J. 2014, 61, 101-110. [CrossRef]

80. Punnia-Moorthy, A. Evaluation of $\mathrm{pH}$ changes in inflammation of the subcutaneous air pouch lining in the rat, induced by carrageenan, dextran and Staphylococcus aureus. J. Oral. Pathol. 1987, 16, 36-44. [CrossRef]

81. Di Pompo, G.; Lemma, S.; Canti, L.; Rucci, N.; Ponzetti, M.; Errani, C.; Donati, D.M.; Russell, S.; Gillies, R.; Chano, T.; et al. Intratumoral acidosis fosters cancer-induced bone pain through the activation of the mesenchymal tumor-associated stroma in bone metastasis from breast carcinoma. Oncotarget 2017, 8, 54478-54496. [CrossRef] [PubMed]

82. Nagasaka, A.; Mogi, C.; Ono, H.; Nishi, T.; Horii, Y.; Ohba, Y.; Sato, K.; Nakaya, M.; Okajima, F.; Kurose, $\mathrm{H}$. The proton-sensing $\mathrm{G}$ protein-coupled receptor T-cell death-associated gene 8 (TDAG8) shows cardioprotective effects against myocardial infarction. Sci. Rep. 2017, 7, 7812. [CrossRef] [PubMed]

83. Chen, Z.; Yu, R.; Xiong, Y.; Du, F.; Zhu, S. A vicious circle between insulin resistance and inflammation in nonalcoholic fatty liver disease. Lipids Health Dis. 2017, 16, 203. [CrossRef] [PubMed]

84. Zhang, J.; Wu, W.; Li, D.; Guo, Y.; Ding, H. Overactivation of NF-kappaB impairs insulin sensitivity and mediates palmitate-induced insulin resistance in C2C12 skeletal muscle cells. Endocrine 2010, 37, 157-166. [CrossRef] [PubMed]

85. Jiang, H.; Ma, Y.; Yan, J.; Liu, J.; Li, L. Geniposide promotes autophagy to inhibit insulin resistance in HepG2 cells via P62/NFkappaB/GLUT4. Mol. Med. Rep. 2017, 16, 7237-7244. [CrossRef] [PubMed]

86. Sauter, N.S.; Schulthess, F.T.; Galasso, R.; Castellani, L.W.; Maedler, K. The antiinflammatory cytokine interleukin-1 receptor antagonist protects from high-fat diet-induced hyperglycemia. Endocrinology 2008, 149, 2208-2218. [CrossRef] [PubMed]

87. Feve, B.; Bastard, J.P. The role of interleukins in insulin resistance and type 2 diabetes mellitus. Nat. Rev. Endocrinol. 2009, 5, 305-311. [CrossRef]

88. Robey, I.F.; Baggett, B.K.; Kirkpatrick, N.D.; Roe, D.J.; Dosescu, J.; Sloane, B.F.; Hashim, A.I.; Morse, D.L.; Raghunand, N.; Gatenby, R.A.; et al. Bicarbonate increases tumor $\mathrm{pH}$ and inhibits spontaneous metastases. Cancer Res. 2009, 69, 2260-2268. [CrossRef]

89. Della Guardia, L.; Thomas, M.A.; Cena, H. Insulin Sensitivity and Glucose Homeostasis Can Be Influenced by Metabolic Acid Load. Nutrients 2018, 10, 618. [CrossRef] 